\title{
Thermal Insulation Using Agricultural By-Product: A Review
}

\author{
P.S. Dhivar, A.R. Patil \\ (Department of Mechanical Engineering, MES College Of Engineering, Pune -1)
}

\begin{abstract}
Thermal insulation in the very beginning were made from materials available in nature which mostly included animal shin, wool, flax or straw, etc. The drawback of these materials was that their lifespan was limited because of which artificial materials for insulation came into picture. With regard to the requirements of current environmental condition it is necessary in the construction and reconstruction of existing buildings to implement effective measures for reducing their energy consumption. In actual it is virtually important to get all new building, old buildings with almost zero energy consumption. From the perspective of sustainable development and environmental concern (CO2 emissions) the thermally insulating materials based on natural organic fibers are a better alternative to synthetic thermal insulation of mineral fibers and foam-plastic substances. The main disadvantages of the thermal insulation materials based on natural materials, which very often denies their use in thermal insulation systems structures are: high water absorption and poor response to fire. This paper seeks to discuss the possibility of developing insulation materials made of non-industrial crop wastes and natural binders, for the construction sector and other applications. The agricultural waste that are studied are rice husk, corn cob, coco coir ,palm fiber etc .Experiments are performed on specimens using different natural binders and components that will enhance the insulation properties of the specimens. The experimental methods and results show that natural insulators can be good alternative for thermal insulation in now a day application. The procedure for preparation of specimen is also mentioned in this paper. The results mentioned include the thermal conductivity of the specimen prepared which shows the insulation ability of specimen.
\end{abstract}

Keywords: Agriculture by-products, Natural organic fibers, Sustainable, Thermal conductivity, Thermal insulation

\section{INTRODUCTION}

From the pre historic period thermal insulation has been a necessity to protect ourselves from cold and hot environment. People started using animal skin, fur, wool and plant based products like reed, straw or flax. These products had a short life span. Man built caves and house made from wood, stone and earth. Caves were properly insulated as they were cut into mountains made of sol and stones which were great thermal insulators. The earth houses used soil for making houses. This soil worked as a great insulator, as due to high density of soil the inside temperature changes very slowly. This phenomenon is called as thermal lag i.e the insulator keeps the inside cool in summers and warm in winters [1].Thermal insulation can defined as property of a material which helps in reduction of heat transfer between objects in thermal contact with both the body at different temperatures. Heat flows from high temperature body to low temperature body when they are in contact or have a medium between them for heat transfer. This heat flow between the bodies cannot be stopped. The insulating capability of a material is measured with thermal conductivity. Lesser the thermal conductivity more will be the thermal insulating capability of the material used as insulator[1]. Thermal insulators used now-adays are made from artificial products such as fiberglass, mineral wool, polyurethane foam, polystyrene, glass wool, rock wool, etc. These insulations are costly and few of them like glass wool and rock wool are carcinogenic in nature. According to study it has been found that fiberglass is carcinogenic and while installing this insulator one might feel itching, redness of skin and breathing issues. Polyurethane foam is highly flammable whose smoke contains carbon monoxide, benzene etc. which is not good for environment as well as humans [2].These by-products are required to be processed just to increase the resistance to moisture and fire. Different natural binders are also used to keep the material together. Mostly while using agricultural by-products they are drawn into fibers of various diameters which helps in binding the fibers together easily. The insulators made from these by-products are far better than the artificial insulating materials used. The natural insulators inherit the property of absorbing and releasing moisture without affecting its performance Natural insulators can achieve a thermal conductivity as low as $0.035 \mathrm{~W} / \mathrm{m} \mathrm{K}$ [2].This paper contains study of agricultural by-products such as palm fiber, coconut husk, banana fiber, etc which can be used as thermal insulator rather than the artificial insulators. 


\section{PALM FIBER}

A. Oushabi et . al [3] conducted an experiment to test the thermal conductivity of palm fiber and to know whether it is suitable to be used as thermal insulation. The local date palm fibers are used for the study. Seven different varities of palm wood were examined namely, Khalt, Boufeggous, Bu-Slikhen,Mejhoul,Admou, Khalt Zhar and Tazaout. The experiment is done to study the possibility of sing the sheaths, midribs, petioles ,spathes, spikelets and dried leaflets as insulating material for reducing the heat loss in the air conditioning and refrigeration sectors. The fibers of the specimens are seperated manually, washed in water and then dried in oven at 60 degrees for 24 hours. Different tests are performed on the specimen:Water uptake test: The palm fiber samples were cut into small pieces which were then immersed in distilled water. The samples initially showed high rate of moisture sorption and then it shows a slower absorption rate in the later stages (Kumar and Flynn, 2006) which can be explained by the hydrophilic nature of this type of wood and the reactivity of its chemical components consisting essentially of cellulose and hemicelluloses . From the samples density versus immersion time the water absorption behavior was studied. The results are shown in Fig. below:

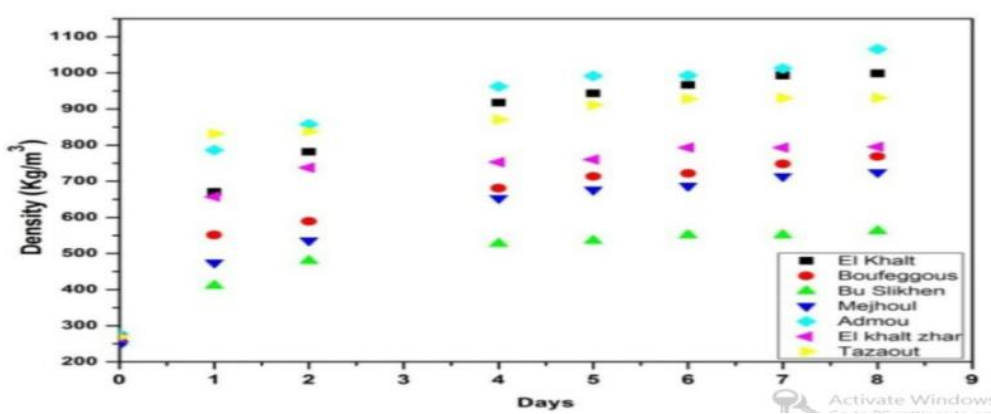

Figure 2.1 Density v/s Days (soaking time)

Mass loss determination: The specimen is washed with water and air dried at different temperatures for 24 hours. The mass loss is determined by formula below.XL $(\%)=(\mathrm{XO}-\mathrm{X})$

$\mathrm{XO}$

Where, $\mathrm{XL}=$ percentage of mass lost $\mathrm{XO}=$ mass after drying

$\mathrm{X}=$ mass before drying

The density of fibers is determined by the formula

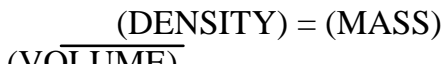

(VOLUME)

The results show the density and mass loss at different drying temperatures.

The Fig. below shows the results for all seven specimens after experiment
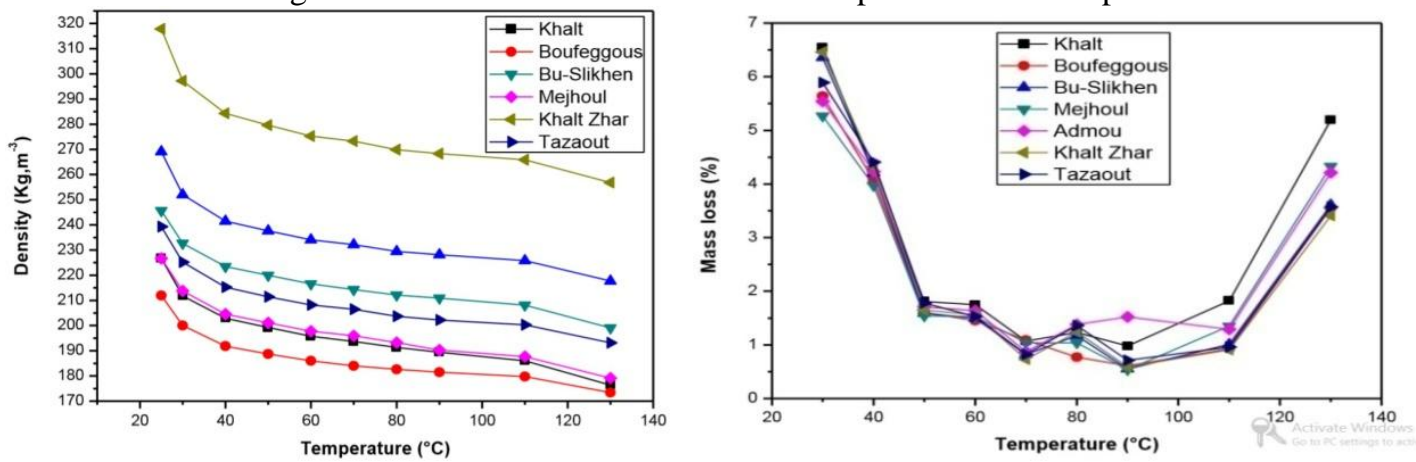

Figure 2.2 Results for mass loss determination test

Scanning electron microscopy: The fibers are prepared and scanned under SEM. The surface structure of fibers is checked to evaluate the pore structure and pore distribution. 

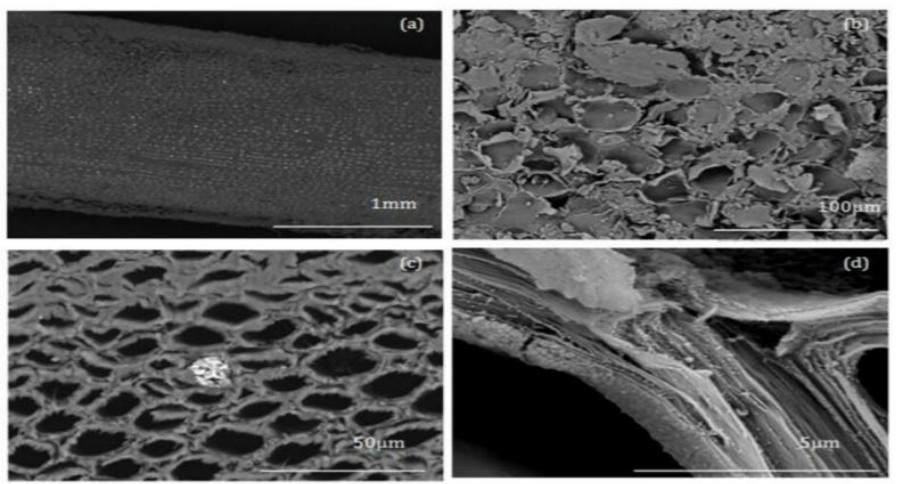

Figure 2.3 Images of the Boufeggous fibre at (a) $1 \mathrm{~mm}$ (b) $100 \mu \mathrm{m}$ (c) $50 \mu \mathrm{m}$ and (d) $5 \mu \mathrm{m}$

Thermal conductivity testing: From above above experiments the characteristics related to thermal conductivity of the specimen are observed. A hot wire method is used as measurement technique to measure the thermal conductivity. It is measured at 25 degrees. From the experiment performed the thermal conductivity of wood of palm is $0.041 \mathrm{~W} / \mathrm{m} \mathrm{K}$ and sample effusivity is about $163.36 \mathrm{Ws}^{\wedge} 0.5 / \mathrm{m}^{\wedge} 2 \mathrm{~K}$.

\section{BANANA FIBER}

Krishpersad Manohar [4] studied the banana fiber to be used as thermal insulator. He performed experiments to determine the properties of banana fiber. According to the study the long fibers in the banana tree comprise $1.5 \%$ of the total mass of the plant. The trunk of the banana tree is a material like soft leaf and have a high fiborous content. The comparitively long fibers of the banana tree are a very good alternative for use as a thermal insulation. The results of the study of lignocellulos materials has showed that these materials prove to be a have appreciable thermal insulation properties if managed effectivelygiving a net reduction in $\mathrm{CO} 2$ emission.Banana fiber sample preparation: As the buyers for banana fiber are very erractic therefore there is no commercial machine for extraction of banana fibers. Therefore an experimental slotted barrel rotating machine was used for extracting the banana fibers. For extracting the fibers from the machine the trunk is being processed. The trunk is peeled and cut in strip of 10 to $15 \mathrm{~cm}$ width, only the outer layer is used. In banana trunk, innermost part contained soft fibers hence it was not used. The fibers to be used were air dried for seven days after which they were cut and after thst were sorted.Specimen preparation: A square specimen of $50.4 \mathrm{~mm}$ thickness and $25.4 \mathrm{~mm}$ side. The specimen had fibers which were randomly packed in a $50.4 \mathrm{~mm}$ high polystyrene specimen holder made with $25.5 \mathrm{~mm}$ thick strips of polystyrene. The specimen of different densities were tested. The density variation was made according to the calculations done my calculating the mass of fiber using the volume of specimen holder and its target density. The specimen for testing were prepared of different densities in the range of $20 \mathrm{~kg} / \mathrm{m} 3$ to $120 \mathrm{~kg} / \mathrm{m} 3$. Result : A Heat Flow Meter Apparatus was been used to study the thermal transmission. A $102 \mathrm{~mm}$ x $102 \mathrm{~mm}$ heat flux transducer was placed centrally on plates with constant temperature. The temperature difference of $20 \mathrm{oC}$ was maintained between hot and cold plate. The sppecimen of different densities were placed in the test apparatus. These specimens were tested at different temperatures. The result of test for different density specimen at different temperatures is given in Table 3.1.

Table 3.1 Experimental determined thermal conductivity

\begin{tabular}{|l|l|l|l|l|l|}
\hline \multirow{2}{*}{$\begin{array}{l}\text { Density } \\
\left(\mathbf{k g} / \mathbf{m}^{\mathbf{3}}\right)\end{array}$} & \multicolumn{5}{|l|}{ Experimental Determined Thermal Conductivity (W/m.K) } \\
\cline { 2 - 6 } & $\mathbf{2 0} \square \mathbf{C}$ & $\mathbf{2 5} \square \mathbf{C}$ & $\mathbf{3 0} \square \mathbf{C}$ & $\mathbf{3 5} \square \mathbf{C}$ & $\mathbf{4 0} \square \mathbf{C}$ \\
\hline 20 & 0.06679 & 0.06902 & 0.07135 & 0.07367 & 0.07533 \\
\hline 30 & 0.05341 & 0.05499 & 0.05679 & 0.05855 & 0.05939 \\
\hline 40 & 0.04816 & 0.04935 & 0.05096 & 0.05264 & 0.05395 \\
\hline 50 & 0.04612 & 0.04674 & 0.04747 & 0.04850 & 0.04985 \\
\hline 60 & 0.04355 & 0.04443 & 0.04520 & 0.04576 & 0.04677 \\
\hline 70 & 0.04231 & 0.04392 & 0.04611 & 0.04567 & 0.04648 \\
\hline 80 & 0.04202 & 0.04275 & 0.04436 & 0.04484 & 0.04495 \\
\hline 90 & 0.04389 & 0.04466 & 0.04529 & 0.04593 & 0.04495 \\
\hline 100 & 0.04496 & 0.04509 & 0.04573 & 0.04607 & 0.04523 \\
\hline 110 & 0.04647 & 0.04667 & 0.04740 & 0.04839 & 0.04958 \\
\hline 120 & 0.04854 & 0.04921 & 0.05013 & 0.05141 & 0.05248 \\
\hline
\end{tabular}

The emperical relation used for calculation of thermal conductivity is as follows

$$
\lambda=\mathrm{a}+\mathrm{b} \rho+\mathrm{c} / \rho
$$

where, $\lambda=$ thermal conductivity in $\mathrm{W} / \mathrm{m} . \mathrm{K}$

$\rho=$ density in $\mathrm{kg} / \mathrm{m} 3$ 
$\mathrm{a}, \mathrm{b},=$ numerical constants

From the results we understand that the lowest thermal conductivity value was obtained at a density of 70.4 $\mathrm{kg} / \mathrm{m} 3$ which was $0.04415 \mathrm{~W} / \mathrm{m} . \mathrm{K}$ (theoretical) and was $0.04231 \mathrm{~W} / \mathrm{m} . \mathrm{K}$ at a density of $70 \mathrm{~kg} / \mathrm{m} 3$ (experimentaly).

\section{CORN COB}

Paiva A et . al [5] studied the material properties of corn cob. Anisotropy and material discontinuity are two material characteristics of corn cob. The density of corn cob according to a study was measured to be $212.11 \mathrm{~kg} / \mathrm{m} 3$. The corn cob has excellent water absorbtion capacity of about $327 \%$. Pinto J et. al [6] performed tests on corn cob to determine the thermal conductivity of corn cob.For experiment: The experiments were carried out on a test specimen with dimension $4 * 3 * 2.54 \mathrm{~m}$ (length*width*height). The orientation of test specimen is done in such a way that there is no incidence of solar radiations on the specimen and it is also away from rain. It is important to ensure that the temperature gradient between the inside and outside of the test room remains approximately constant. This ensures the same type of heat flow always. Equipment : Two thermohygrometric devices and a flux meter is used in this experiment. Each heat flux meter contains two heat flux sensors. The heat flux meter system and thermohygrometric device is shown in the Figure below:The temperature gradient between the indoor and outdoor of test room is measured using the heat flux sensors. The thermohygrometric device has two probes, one is used to measure the temperature and other is used to measure the humidity. There are two thermohygrometric devices used for the same purpose but one for indoor and one for outdoor.Calculation methodology: The thermal transmission coefficient (U) of a material or a building system can be quantified given the heat flow that occurs through the element when submitted to a temperature differential, as presented in Expression (1):

$$
U(\text { ntotal })=\frac{\sum_{n=1}^{\text {ntotal }} q(n)}{\sum_{n=1}^{\text {notal }}(T i(n)-T e(n))}
$$

where, $\mathrm{q}(\mathrm{n})=$ heat flow across the element in the moment $\mathrm{n}$

$\operatorname{Ti}(\mathrm{n})$ and $\operatorname{Te}(\mathrm{n})=$ interior and the exterior temperatures in the moment $\mathrm{n}$, respectively;

Ntotal $=$ total number of moments The values for $q 1(n)$ and $q 2(n)$ is obtained by using heat flux meter.

The thermal transmission coefficient U1(ntotal) and U2(ntotal), can be estimated by considering Ti(n) and Te(n) accordingly. By applying equation one we get,

$$
\mathrm{U}(\text { ntotal })=\frac{\mathrm{U} 1(\text { ntotal })+\mathrm{U} 2(\text { ntotal })}{2}
$$

If the temperature is stable arount the heat flux meter then a minimum test duration of 3 days is required: if it is not so then the test is carried out for 7 days or more. This criteria is considered because the heat flux must be stable for proper results. The heat flux generated through the specimen depends on the capacity of storage of specimen and the thermal intertia. Few errors may arrive due to improper contact between surface of specimen and sensors, accuracy of instrument, accuracy of data aquasition system, etc.Granulated corn cob is prefferd formaking specimen because of its low thermal inertia the duration of test will be 3 days only and will be giving approximately accurate results. The corn cob is granulated to required size granules by using a cutting mill device which is provided with a sieve whose size range is from 0.25 to $20 \mathrm{~mm}$.

The prepared specimen was tested for 8 days and the obtained results are shown in the Fig. below:

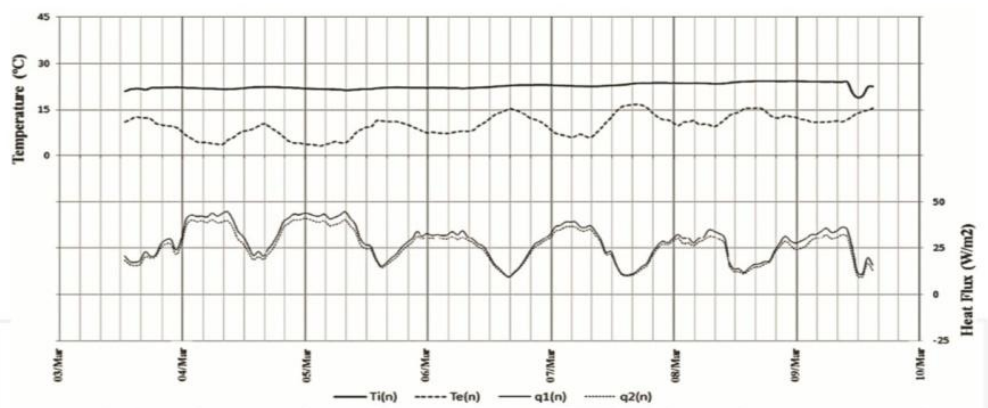

Figure 4.1temperature v/s heat flux 
From the chart and required calculation the thermal conductivity of granulated corn cob is $0.058 \mathrm{~W} / \mathrm{moC}$. This shows that the granulated corn cob can prove to be a great thermal insulator.

\section{HEMP}

V. Virginia et . al [8] prepared hemp sampels by adding different solutions which were tested for thermal conductivity. these tests also suggested the best way to obtain maximum thermal insulation. Wettability of a material which is to be used as thermal insulation must be low. This is because, the more the wettability of material more is the thermal conductivity which is not desirable. In this paper we will study that how hemp can be made suitable to be used as a thermal insulator. Test samples and methodology of experiment: The hemp sample for experiment was prepared using polyester bicomponent fibres(15\%) by thermal bonding process.

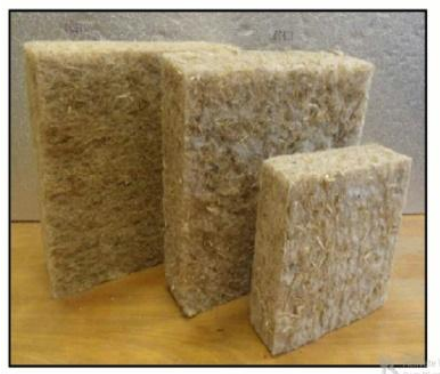

Figure 5.1 Test sample

The dimensions of the specimens were $200 \times 200 \mathrm{~mm}$ and $300 \times 300 \mathrm{~mm}$. Different products were used to apply over the specimen make. The compatible impregnations were selected on the basis of market research and previous studies done. Therefore the following products are used for the hydrophobic tratement of specimen

- Hexadecyltrimethoxysilan (HDTMS);

- Water-glass;

- Draxil 153 -product based on siloxanes;

- Lukofob 39 -product contains potassium methyl siliconate - more than $50 \%$ by weight; distilled water was used as a solvent for preparing the solutio);

- Tagal- product contains isopropyl alcohol - from $10 \%$ to $20 \%$ by weight, gasoline (petroleum) fraction - from $50 \%$ to $90 \%$ by weight, and isopropyl acetate - from $1 \%$ to $5 \%$ by weight

- Tris (2-methoxyethoxy) (vinyl) silan (TMEVS);

These products were applied on specimen either by dipping or spraying. A solution of silica was prepared using aqueous solutionHCl and sodium water- glass. The solution prepared contained $\mathrm{HCl}$,distilled water and sodium water-glass in the ratio 1:8:1. Another solution was prepared using the same method as above just that it was added with with hydrolysed HDTMS (4\% by weight). The specimen was further treated with these two solutions also. An another solution of just sodium water glass and distilled water in the ratio 1:8 was preapared and used to treat the specimen. The specimen treated with all different solutions or applied products is tested. These specimens were first dried in the laboratory and then it is dried in the oven. These samples were subjected to different testings from which the length, width, thickness, mass density, short-term absorbability, hygroscopic sorption moisture and thermal conductivity was detemined.

The results of the experiment are shown in the Table below:

Table 5.1

\begin{tabular}{lll}
\hline Sample & $\lambda_{\text {dry }}$ (dry state) $\left[\mathrm{W} \cdot \mathrm{m}^{-1} \cdot \mathrm{K}^{-1}\right]$ & $\lambda_{23,80}$ (with sorption moisture) $\left[\mathrm{W} \cdot \mathrm{m}^{-1} \cdot \mathrm{K}^{-1}\right]$ \\
\hline REF & 0.04363 & 0.06257 \\
\hline H6 & 0.04430 & 0.05898 \\
\hline T6 & 0.04632 & 0.06179 \\
\hline LUK & 0.04873 & 0.06450 \\
\hline DR & 0.04751 & 0.06219 \\
\hline TG & 0.05053 & 0.06746 \\
\hline VS & 0.04527 & 0.06815 \\
\hline VSH & 0.04793 & 0.06737 \\
\hline VSHH & 0.04951 & 0.07114 \\
\hline
\end{tabular}


The results from the result table show that the thermal conductivity of dry hemp specimen is lesser than that of the specimen with sorption moisture retained in it. The minimum thermal conductivity of hemp according to the experiment is $0.04363 \mathrm{~W} / \mathrm{mK}$ which poves that hemp if treated properly can be used as a thermal insulator.

\section{SUNFLOWER STALK}

Mariana Palumbo et . al [9]studied thermal insulation properties of sunflower stalk. The sunflower stalks are not used for any purpose. Research has proved that due to low density of sunflower stalk it can prove to be a good thermal insulator.Method of preparation: The stalks of sunflower are harvested from the field manually and are hammered and made flat to a particle size $12 \mathrm{~mm}$. The stalk consists pith which is to be used for the further experiment. This pith is then removed from the stalk by using pulsed air. The pith is then reduced to a particle size of $5 \mathrm{~mm}$ using a knife. A lambda meter a hot plate apparatus is used for the measurement of thermal conductivity. The experiment is performed at three temperatures $10^{\circ} \mathrm{C}, 25^{\circ} \mathrm{C}$ and $40^{\circ} \mathrm{C}$. The dimension of plate is $15 \mathrm{~cm} \times 15 \mathrm{~cm} \times 5 \mathrm{~cm}$ which is kept in a box of polycarbonate of $1 \mathrm{~mm}$ thickness. The sunflower pith is kept directly on the plate while performing the exeriment. The specimen is ready for experiment after the absorption of $3 \mathrm{~g}$ of water per $1 \mathrm{~g}$ of pith which is then dried at $150^{\circ} \mathrm{C}$.

Result of experiment: The density and composition were determined using Van Soest and Wine method. The result is shown below:

Table 6.1 Composition obtained by using Van Soest and Wine method

\begin{tabular}{|l|l|l|l|l|l|l|}
\hline & & $\begin{array}{l}\text { Lignins } \\
(\%)\end{array}$ & density & $\begin{array}{l}\text { Ash } \\
(\%)\end{array}$ & $\begin{array}{l}\text { Hemicelluloses } \\
(\%)\end{array}$ & $\begin{array}{l}\text { Cellulose } \\
(\%)\end{array}$ \\
\hline Sunflower & $\begin{array}{l}\text { Sunflower } \\
\text { pith }\end{array}$ & $\begin{array}{l}0.018- \\
0.035\end{array}$ & 17 & $4-$ & 45 & $3-7$ \\
\hline
\end{tabular}

The results for thermal conductivity are given in Table below:

\begin{tabular}{ccccc} 
& \multicolumn{3}{c}{$\begin{array}{c}\text { Table } 6.2 \\
\text { Thermal conductivity }\left(\mathrm{mW} \cdot \mathrm{m}^{-1} \cdot \mathrm{K}^{-1}\right)\end{array}$} & $\begin{array}{c}\text { Thermal conductity } \\
\text { sunflower agro- } \\
\text { material }\end{array}$ \\
\cline { 2 - 4 } & $10^{\circ} \mathrm{C}$ & $25^{\circ} \mathrm{C}$ & $40^{\circ} \mathrm{C}$ & \\
\hline $\mathrm{d}<1 \mathrm{~mm}$ & 37.80 & 38.50 & 40.35 & 0.036 \\
\hline $\mathrm{d}<1 \mathrm{~mm}$ & 41.90 & 43.20 & 44.35 & 0.080 \\
\hline $\mathrm{d}<1 \mathrm{~mm}$ & 48.60 & 50.15 & 52.40 & 0.152 \\
\hline $1 \mathrm{~mm}<\mathrm{d}<2 \mathrm{~mm}$ & 41.20 & 43.00 & 45.10 & 0.065 \\
\hline $2 \mathrm{~mm}<\mathrm{d}<5 \mathrm{~mm}$ & 39.50 & 41.00 & 42.40 & 0.060 \\
\hline
\end{tabular}

(d: diameter)

The results show that unflower stalk has good thermal insulation properties with the least thermal conductivity of $0.03780 \mathrm{~W} / \mathrm{mK}$ (from Table above).

\section{RICE HUSK}

Satta Panyakaew and Steve Fotios [10]studied the use of agricultural products as thermal insulation. They performed tests on rice husk to determine the thermal conductivity. Rice husk is not majorly used byproduct. The time required for degradation of rice husk is very long due to which they are not put in field. It contains an important amount of silica in it and have a density of $64,27 \mathrm{~kg} / \mathrm{m} 3$. Method of specimen preparation: The rice husk is directly seived to obtain particles of diameter $2,0.5$ and $1 \mathrm{~mm}$. a solution was prepared using starch and alginate mixed with water with a very small amount of vinegar (6\% acidity), a gel is formed. Sodium bicarbonate and vinegar was added to solution of casein and water, this is done to activate latter. Two different sample sizes for each formulation were prepared: 40 × $40 \times 2 \mathrm{~mm}$ and $150 \times 150 \times 30 \mathrm{~mm}$.

Table 7.1 Amount of components added (values in gms)

\begin{tabular}{|c|c|c|c|c|}
\hline & Binder & Water & Vinegar & Sodium bicarbonate \\
\hline S-Rice $(1.0 \mathrm{~mm})$ & 1.0 & 1.17 & 0.40 & \\
\hline A-Rice $(1.0 \mathrm{~mm})$ & 0.05 & 2.21 & 0.42 & \\
\hline C-Rice & 0.11 & 0.48 & 0.33 & 0.17 \\
\hline
\end{tabular}

The water vapour diffusivity resistance factor $(\mu)$ and equilibrium moisture content (EMC) is detemined.EMC was determined experimentaly by using the salt solution method. Water vapour diffusivity resistance factor $(\mu)$ was determined using a saturated solution of $\mathrm{NaOH}$ for the dry cups and $\mathrm{Na} 2 \mathrm{SO} 4$ for wet 
cups. These weights of the samples were checked regularly until a constant change in weight is obtained. The thermal conductivity $(\lambda)$ and thermal diffusivity $(\alpha)$ were measured the electronic thermal analyser.

Result : The results after the xperiment is given in the Table below:

Table 7.2 Result table

\begin{tabular}{|c|c|c|c|}
\hline & $\begin{array}{c}\Delta \\
(\mathrm{kg} / \mathrm{m} 3)\end{array}$ & $\begin{array}{c}\Lambda \\
(\mathrm{W} / \mathrm{mK})\end{array}$ & $\begin{array}{c}\mathrm{A} \\
10-6(\mathrm{~m} 2 / \mathrm{s})\end{array}$ \\
\hline S-Rice & 290 & 0.077 & 0.330 \\
\hline A-Rice & 210 & 0.073 & 0.332 \\
\hline C-Rice & 270 & 0.098 & 0.377 \\
\hline
\end{tabular}

The thermal conductivity of rice husk from the above Table is $0.077 \mathrm{~W} / \mathrm{mK}$ which proves the suitability of rice husk to be used as thermal insulator.

\section{COCONUT HUSK}

Khedari [11] studied the use of coconut husk as thermal insulators.In costal areas the coconuts are grown in abundance. Coconut is widely used in food and also for different non-edible products. The production of coconut all over the world is approximately upto 50 million tonnes from whichabout 15 to 20 million tonnes of husk. The husk is not used a lot comparitively. A hot pressing method that uses urea formaldehyde resin is used for making coconut husk boards which are used as thermal insulators in buildings.

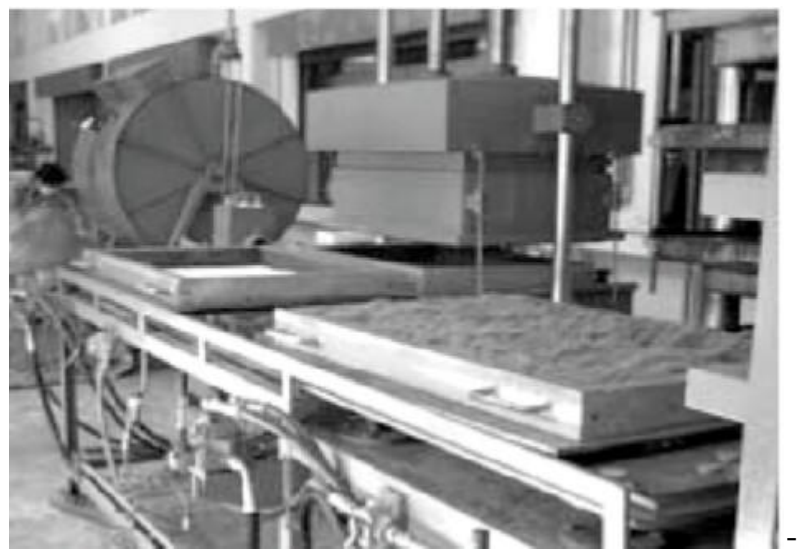

Fig 8.1 Machine used for preparing coconut husk slab

Tests were performed on the board the results of which showed that coconut husk has very low thermal conductivity ranging from 0.054 to $0.143 \mathrm{~W} / \mathrm{Mk}$.

\section{BAGGASE}

Kyauta E.E. Dauda D.M. and Justin E [12]performed experiment on baggase to determine it's thermal conductivity.Sugarcane is grown on a large scale all over the world. Bagasse as such is not used for any purpose therefore it has to be thrown. The disposal adds to the total cost of the money being invested by the industry. To reduce this cost baggase can be used as a thermal insulator as it has low density and low thermal conductivity. A test was carried out on baggase. The baggase was washed with water then dried and then seived to get $1 \mathrm{~mm}$ particle size. It was then soaked in water for 2 hours. Water and $2 \mathrm{~kg}$ clay was mixed. To make the mix homogeneous $774.8 \mathrm{~kg}$ hardner was added to it. This mix was then added with $2.4 \mathrm{~kg}$ baggase and then moulded in brick moulds.

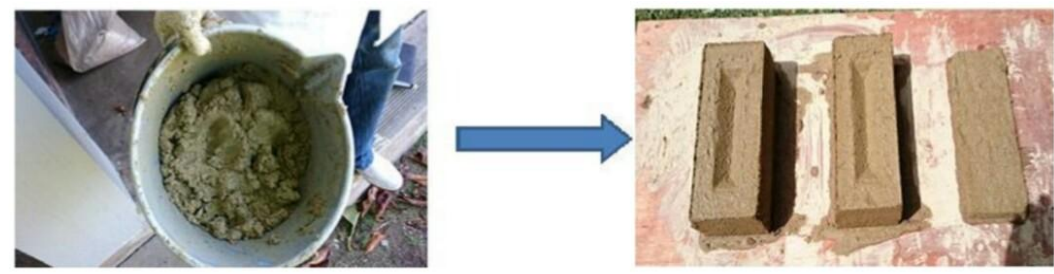

Figure 9.1 Test specimen 
Tests were carried out on this specimen and results showed that the thermal conductivity of baggase is in the range $0.046-0.051 \mathrm{~W} / \mathrm{mK}$. The properties of baggase can be enhanced by bonding baggase with phenolic resin which results in baggase that is strong, durable, light weight, heat and moisture resistant and easily transportable. Baggase can prove to be a good thermal insulator.

\section{DISCUSSION OF RESULTS}

The results from the above review showed that the agricultural by-products will prove to be good thermal insulators. More the thermal conductivity lesser is the thermal insulation. All the reviewed agriculture by-products show impressive thermal insulation properties as their thermal conductivity is very low as that of artificial insulators. The thermal conductivity of all the specimens reviewed is less which shows great thermal insulation properties. The highest thermal conductivity is shown by rice husk which is $0.077 \mathrm{~W} / \mathrm{mK}$ and lowest thermal conductivity is shown by sunflower stalk which is $0.0378 \mathrm{~W} / \mathrm{mK}$. The remaining products in increasing order of thermal conductivity are Palm fiber, Hemp, Banana fiber, Baggase, Coconut fiber. The results below show that sunflower stalk will be a better insulator comparitively. The results can be plotted as shown in the Fig. below:

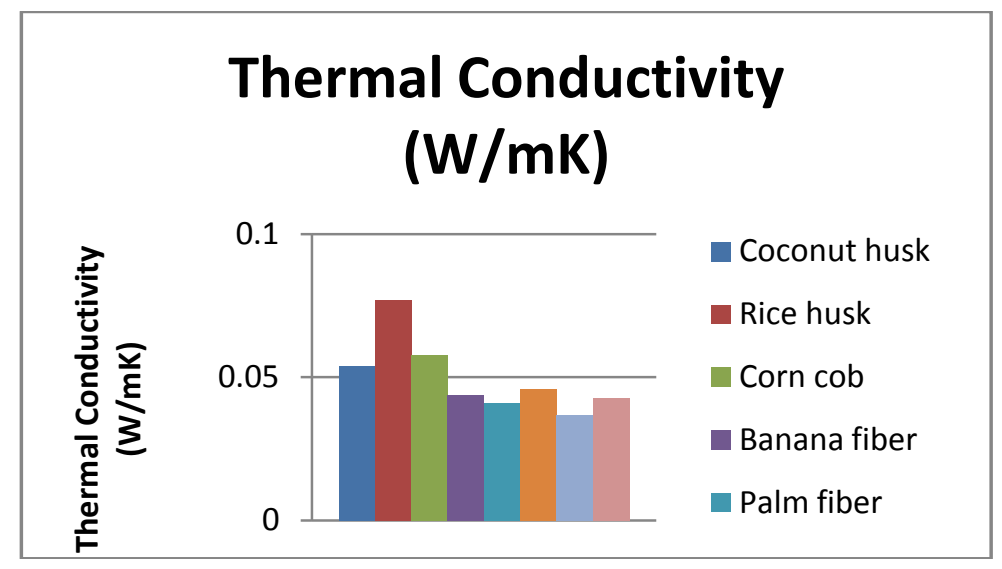

Figure 10

\section{CONCLUSION}

- The insulators made from agriculture by-products are far better than the artificial insulating materials used. The natural insulators inherit the property of absorbing and releasing moisture without affecting its performance. Due the high density, fibrous nature and flexibility of natural fibrous insulations they again perform better than the synthetic insulators acoustically.

- Natural insulators can achieve a thermal conductivity as low as $0.035 \mathrm{~W} / \mathrm{m} \mathrm{K}$.

- The tests have showed that the thermal insulation properties of the products can be increased by addition of some solutions and binders. This enhances the material properties of the product.

- he risk of environmental pollution is reduced if these products are brought into use. The green house gas emissions and carbon foot printing can also be reduced by use of these products. As the products are natural they are also bio-degradable. These products are non-carcinogenic. The use of these products will not cause skin irritation, itching etc that is caused by artificial thermal insulation.

- Efforts should be taken to bring the thermal insulators made from agriculture by-products in actual practice as this will result in lesser pollution and better insulation. Further study can be done on increasing the thermal insulating capacity of the products.

\section{REFERENCES}

[1] Dávid Bozsaky, The historical development of thermal insulation materials, Ŕ periodica polytechnica

[2] Architecture 41/2 (2010) 49-56 doi: 10.3311/pp.ar.2010-2.02, 2011

[3] Pinto J, Cruz D, Paiva A, Pereira S, Tavares P, Fernandes L, Varum H. Characterization of corn cob as a possible raw building material, Constr Build Mater 2012;34:28-33.

[4] A. Oushabi et . al Natural thermal-insulation materials composed of renewable resources: characterization of local date palm fibers (LDPF), Natural thermal-insulation materials composed of renewable resources: characterization of local date palm fibers (LDPF),J. Mater. Environ. Sci. 6 (12) (2015) 3395-3402 ISSN : 2028-2508 CODEN: JMESCN 
[5] Krishpersad Manohar, A Comparison of Banana Fiber Insulation with Biodegradable Fibrous Thermal Insulation, American Journal of Engineering Research (AJER) e-ISSN: 2320-0847 p-ISSN : 2320-0936 Volume-5, Issue-8, pp249-255, 2016

[6] Paiva A, Pereira S, Sá A, Cruz D, Varum H, Pinto J. A contribution to the thermal insulation performance characterization of corn cob particleboards, Energy Build 2011. doi: 10.1016/j.enbuild.2011.11.019.

[7] Vandenbossche Virginia et . al, New agro-materials with thermal insulation properties

[8] Chow P. Dry Formed Composite Board from Selected Agricultural Residues. World Consultation on Wood Based Panels, Food and Agriculture Organization of the United Nations, New Delhi, India, 1974.

[9] Mariana Palumbo et . al, Characterization of thermal insulation materials developed with crop wastes and natural binders, World SB14 Barcelona october 2014

[10] Jiří Zacha,*, Jitka Hroudováb, Jiří Brožovskýc, Zdeněk Krejzad, Albinas Gailiuse, Development of Thermal Insulating Materials on Natural Base for Thermal Insulation Systems, 11th International Conference on Modern Building Materials, Procedia Engineering 57 ( 2013 ) 1288 - 1294

[11] Satta Panyakaew and Steve Fotios, Agricultural Waste Materials as Thermal Insulation for Dwellings in Thailand: Preliminary Results, PLEA 2008 - 25th Conference on Passive and Low Energy Architecture, Dublin, 22nd to 24th October 2008

[12] Khedari, J., (2003). New insulating particleboards from durian peel and coconut coir,. Building and Environment, 38 : p. 435-441.

[13] Kyauta E.E. Dauda D.M. and Justin E ,Investigation on Thermal Properties of Composite of Rice Husk, Corncob and Baggasse for Building Thermal Insulation, American Journal of Engineering Research (AJER) e-ISSN : 2320-0847 p-ISSN : 2320-0936 Volume-03, Issue-12, pp-34-40 